www.jmscr.igmpublication.org

Index Copernicus Value: 79.54

ISSN (e)-2347-176x ISSN (p) 2455-0450

crossref DOI: https://dx.doi.org/10.18535/jmscr/v7i4.119

\title{
Histo-morphological Spectrum of Hansen's Disease with Clinical Concordance at Tertiary Care Centre
}

\author{
Authors \\ Jain Niharika', Gupta Karuna ${ }^{2 *}$ \\ ${ }^{1}$ Postgraduate Student, ${ }^{2} \mathrm{Sr}$. Professor \\ Department of Pathology, SMS Medical College, Jaipur, Rajasthan, India \\ Corresponding Author \\ Gupta Karuna \\ Email:drkaruna@gmail.com
}

\begin{abstract}
Introduction: Leprosy is a crucial health problem in most of the developing countries of the world and it causes awful disfiguration, physical pain, hardship, leads to isolation, rejection and ostracization. Histopathological study of leprosy is very important in understanding the disease, it's varied manifestation and complications. So clinicopathological correlation is extremely important in patient care and management inspite of considering a single parameter. This study was performed to see various histopathological features of different types of leprosy in skin biopsies and to correlate them with clinical presentation.

Materials and Methods: The study was carried out in Department of Pathology, S.M.S. Medical College, Jaipur (Rajasthan) from January 2017 to June 2018. Based on histopathological examination of Hematoxylin and Eosin stained sections and Fite-Faraco staining for identification of the lepra bacilli, total of 100 specimens of skin biopies were diagnosed.
\end{abstract}

Results: In the present study, maximum number of cases among clinically diagnosed cases belonged to BT 43 (43\%) followed by BL 12 (12\%), TT 9 (9\%), LL 8 (8\%), IL 7 (7\%), BB 3 (3\%). Most of the biopsies were of paucibacillary type (51\%) and the rest (49\%) were of multibacillary type. On histology, BT type was the commonest type of leprosy which constituted $31 \%$ cases followed by TT-18\% cases, LL-18\% cases, BL- 9 \% cases, IL- $9 \%$ cases, BB 3\% cases and Histoid leprosy 3 (3\%). High BI of 5+ to 6+ were noted in LL and HL type and low BI of 1+ to 2+ were observed in TT, BT and BB type. Majority of TT, BT and IL type were negative for lepra bacilli. The overall clinico-histopathological correlation was seen in 55.95\% cases and a good concordance was seen in TT (77.77\%) and LL (75\%) followed by BT (65\%). The least concordance was seen in $B B$.

Conclusion: Histological changes appear earlier than clinical features so biopsy is very useful in diagnosing reactions earlier so that complications can be prevented.

Keywords: Leprosy, Skin biopsy, Histopathology.

\section{Introduction}

Leprosy or Hansen's disease is one of the oldest human epidemic diseases which affected humanity for over 4,000 years. Earliest human who suffered from leprosy was discovered in DNA extracted from a body in a tomb in 
Jerusalem. ${ }^{1}$ It is one of the most feared diseases known and is a disease of intense social stigma leading to human discrimination. Individuals who had leprosy were isolated as outcasts and sent outside the city in lepra colonies. In the 13th century in France there were more than 2000 leprosaria. $^{2}$

Leprosy is caused by Mycobacterium Leprae which affects cooler parts of body primarily skin and peripheral nerves and may also involve muscles, eyes, bones, testis and internal organs. It can occur at all ages with almost equal incidence in both sexes. ${ }^{3-5}$

Worldwide there were 265661 cases in 2006, 211903 cases in 2010 and 211973 cases in 2015 of leprosy. There was a marginal increase in 2016 to 214783 cases. This increase is attributed to active case-finding approaches being adopted by national programmes and improved reporting and data collection. A prevalence rate of leprosy has reduced from $>5$ million cases in the mid-1980s to $<200000$ cases at the end of $2016 .{ }^{5}$ The highest incidence is seen in India (about 60\% with 127326 cases) followed by Brazil and Indonesia. Although WHO goal to eliminate leprosy by the year 2000 has not been achieved, the success of control measures has been groundbreaking especially the introduction of multidrug therapy. ${ }^{6}$

For the correct and adequate treatment, the diagnosis must be made early and it should be accurate so that manifestations and complications can be reduced to minimum. Histopathological study of leprosy has a vital role in understanding the disease pathology, it's manifestation and complications. So clinicopathological correlation is extremely important in patient care and management of the disease.

This study was planned to see patterns of Hansen's disease, to identify various lepra reactions in skin biopsies and to correlate them with clinical presentation. Bacillary Index and Morphological Indexwere also calculated in all cases to make more appropriate diagnosis.

\section{Materials and Methods}

Alaboratory based cross sectional observational study wascarried out in Department of Pathology, SMS Medical College, Jaipur (Rajasthan) from January 2017 to June 2018. Prior approval from institutional ethics committee was taken and skin biopsies received from Department of Dermatology of the institute were examined. Total of 153 skin punch biopsies from clinically diagnosed leprosy patients were received during the study period, out of them 100 biopsies were included in the study which showed histological evidence of leprosy.

The tissue was fixed in $10 \%$ formalin for histopathological examination. Then paraffin embedded blocks were made in the usual manner and thin sections of 3-4 microns were cut by using a microtome. Sections are stained by haematoxylin \& eosin stains for morphological assessment and with Fite-Faraco stain for identification of the lepra bacilli. The sections were examined for epidermal atrophy, granulomas, and infiltrates of lymphocytes, histiocytes, foam cells, infiltration of nerves, blood vessels, and adnexa, and the presence of Grenz zone. Bacillary index was assessed under oil emersion using $100 \mathrm{x}$ objective. After studying the histopathological features and noting the bacteriological index, the diagnosis of leprosy was confirmed and classified according to Ridley and Jopling classification. Subsequently, a correlation was made between the histo-pathologic and clinical classification.

\section{Results}

During the study period around 1220 skin biopsies were received from Department of Dermatology, out of them 153 skin biopsies were diagnosed as leprosy clinically, which constituted $12.54 \%$ of the total skin biopsies. The present study included 100 skin biopsies from the patients who were histologically confirmed for leprosy.

The majority of patients were male (67\%) and $33 \%$ were female patients, with male to female ratio of 2.03. The age ranged from 9 years to 76 
years. Among them majority of the patient $(21 \%)$ were in $4^{\text {th }}$ decade, followed by $5^{\text {th }}$ decade $(18 \%)$ and $3^{\text {rd }}$ decade (17\%) (Table-1). Hypo anaesthesia was most common presenting symptom found in $89 \%$ cases. There were $76(76 \%)$ cases presented with hypo pigmented lesion and $24(24 \%)$ cases presented with erythematous lesion. $10 \%$ cases had nodules and $66 \%$ cases had thickened nerves (Figure-1).

Clinically highest number of cases belonged to BT (43\%) followed by BL (12\%), TT (9\%), LL (8\%), IL (7\%), BB $3(3 \%)$ and Histoid leprosy (3\%) while histologically BT (31\%) was most common type followed by TT (18\%), LL (15\%), BL (9\%), $\mathrm{IL}(9 \%)$ and $\mathrm{BB}(3 \%)$ being least common. Biopsy from 12 patients who were already on MDT also received out of them 6 cases were active while other 6 were inactive (Figure-2).

Epidermis was found unremarkable in $51 \%$ cases, thinned out in $49 \%$ (IL-3\%, TT-8\%, BT-6\%, BB$3 \%$, BL-7\%, LL-13\%, Histoid 3\%, active-4\% and inactive-2\%) cases. Dermis infiltrate found predominantly of epithelioid cells (65\% cases) followed by infiltrate of macrophages (26\% cases), of spindle shaped histiocytes (3\% cases) and of few lymphohistiocytic cells (12\% cases). Giant cells were present in $26 \%$ cases. Lymphocytes in form of collar around granulomas were present in $52 \%$ cases while only at one pole of granuloma were present in $13 \%$ cases. Nerve appears involved and thick in $11 \%$ cases, only involved in $38 \%$ cases, uninvolved in $23 \%$ cases, twigs in $4 \%$ cases, onion skin perineurium in $15 \%$ cases and hyalinised in 9\% cases (Table-2).

$51 \%$ cases were paucibacillary and $49 \%$ cases were multibacillary. Majority of paucibacillary cases were covered by IL, TT and BT while multibacillary group had BB, BL, LL, HL and on MDT cases which had active lesion. Majority 7 (77.8\%) of IL cases were paucibacillary with only $1(22.22 \%)$ case showed BI of +1 . Among TT group $16(88.89 \%)$ cases were paucibacillary and $2(11.11 \%)$ cases were multibacillary with $\mathrm{BI}+1$. Among BT group, 22 (70.96\%) cases were paucibacillary, 5 (16.12\%) cases had BI of +1 and $4(12.9 \%)$ cases with BI +2 . Among BB group, 2 $(66.66 \%)$ cases had $\mathrm{BI}+4$ and $1(33.33 \%)$ case had BI +3. Among BL group, $5(55.55 \%)$ cases had BI of +4 and $4(44.44 \%)$ cases have BI +5 . Among LL group, 6 (40\%) cases have BI of $+6,5$ $(33.33 \%)$ cases had BI +5 and $4(26.66 \%)$ cases had BI +4. Among HL group, 3 (100\%) cases had $\mathrm{BI}$ of +6 . In active disease group, $5(83.33 \%)$ cases had $\mathrm{BL}+1$ and $1(16.67 \%)$ case was paucibacillary. In inactive disease group, 5 $(83.33 \%)$ cases were paucibacillary and 1 (16.67\%) case had BL +1 (Table-3).

In the present study, out of 9 cases which were clinically diagnosed as TT, 7 (77.77\%) was of TT type, $1(11.11 \%)$ was of BT type and $1(11.11 \%)$ was of IL type on histopathological study. Out of the 43 clinically diagnosed BT cases, 28 (65.11\%) were of BT type, $1(2.32 \%)$ was of BB type, 9 (20.93\%) were of TT, 2 (4.65\%) were of BL type, $1(2.32 \%)$ was of LL type and $2(4.65 \%)$ were of IL type on histopathological study. Out of the 3 clinically diagnosed BB cases, $1(33.33 \%)$ was of TT type and $2(66.66 \%)$ of IL type on histopathological study. Out of the 12 clinically diagnosed BL cases, 6 (50\%) were of BL type, 2 $(16.66 \%)$ were of BB type and $1(8.33 \%)$ was of BT type on histopathological study. Out of the 8 clinically diagnosed LL cases, $6(75 \%)$ were of LL type, $1(12.5 \%)$ was of BL type and 1 (12.5\%) was of HL type on histopathological study. Out of the 7 clinically diagnosed IL cases, 4 (57.14\%) were of IL type and 2 (28.57\%) were of LL and 1 (14.28\%) was of TT type on histopathological study. Out of the 3 clinically diagnosed HL cases, $2(66.66 \%)$ were of HL type and $1(33.33 \%)$ was of LL type on histopathological study. 2 clinically diagnosed ENL cases came out to be of LL type on histopathological study. 1 clinically diagnosed type 1 reaction case came out to be of BT type on histopathological study. There was significant difference between clinical and histological diagnosis $(\mathrm{P}$ value $<0.001)$ (Table-4). 
Table-1: Age and Sex wise distribution in different types of leprosy

\begin{tabular}{|c|c|c|c|c|c|c|c|c|c|c|c|c|c|c|c|c|}
\hline & \multicolumn{2}{|c|}{ IL } & \multicolumn{2}{|c|}{ TT } & \multicolumn{2}{|c|}{ BT } & \multicolumn{2}{|c|}{ BB } & \multicolumn{2}{|c|}{ BL } & \multicolumn{2}{|c|}{$\overline{\mathbf{L L}}$} & \multicolumn{2}{|c|}{$\overline{\text { ACTIVE }}$} & \multicolumn{2}{|c|}{ INACTIVE } \\
\hline AGE & M & $\mathrm{F}$ & M & $\mathrm{F}$ & M & $\mathrm{F}$ & M & $\mathrm{F}$ & M & $\mathrm{F}$ & $\mathrm{M}$ & $\mathrm{F}$ & $\mathrm{M}$ & $\mathrm{F}$ & $\mathrm{M}$ & $\mathrm{F}$ \\
\hline $0-10$ & 0 & 0 & 0 & 1 & 0 & 0 & 0 & 0 & 0 & 0 & 0 & 0 & 0 & 0 & 0 & 0 \\
\hline $11-20$ & 1 & 0 & 4 & 1 & 5 & 2 & 0 & 1 & 2 & 0 & 0 & 0 & 0 & 0 & 0 & 1 \\
\hline $21-30$ & 2 & 1 & 2 & 1 & 4 & 0 & 1 & 0 & 0 & 1 & 2 & 1 & 0 & 0 & 2 & 0 \\
\hline $31-40$ & 0 & 0 & 3 & 2 & 5 & 2 & 1 & 0 & 2 & 2 & 0 & 2 & 1 & 1 & 0 & 0 \\
\hline $41-50$ & 2 & 1 & 3 & 0 & 5 & 1 & 0 & 0 & 0 & 2 & 2 & 0 & 1 & 0 & 1 & 1 \\
\hline 51-60 & 0 & 0 & 1 & 0 & 2 & 1 & 0 & 0 & 0 & 0 & 4 & 1 & 1 & 0 & 0 & 0 \\
\hline 61-70 & 0 & 1 & 0 & 0 & 2 & 1 & 0 & 0 & 0 & 0 & 3 & 0 & 2 & 0 & 0 & 1 \\
\hline $71-80$ & 1 & 0 & 0 & 0 & 1 & 0 & 0 & 0 & 0 & 0 & 3 & 0 & 0 & 0 & 0 & 0 \\
\hline \multirow{2}{*}{$\begin{array}{l}\text { TOTAL } \\
100\end{array}$} & 6 & 3 & 13 & 5 & 24 & 7 & 2 & 1 & 4 & 5 & 14 & 4 & 5 & 1 & 3 & 3 \\
\hline & \multicolumn{2}{|c|}{9} & \multicolumn{2}{|c|}{18} & \multicolumn{2}{|c|}{31} & \multicolumn{2}{|c|}{3} & \multicolumn{2}{|c|}{9} & \multicolumn{2}{|c|}{18} & \multicolumn{2}{|c|}{$\overline{6}$} & \multicolumn{2}{|c|}{6} \\
\hline
\end{tabular}

Table-2: Histopathological changes observed in leprosy

\begin{tabular}{|c|c|c|c|}
\hline & & Histological features & No. of cases \\
\hline \multirow[t]{3}{*}{ Epidermis } & & Unremarkable & 51 \\
\hline & & Thinning & 49 \\
\hline & & Encroachment & 18 \\
\hline \multirow{19}{*}{ Dermis } & \multirow{5}{*}{ Nature of infiltrate } & Epithelioid cells & 65 \\
\hline & & Macrophages & 26 \\
\hline & & Lym-hisiocytes & 12 \\
\hline & & Spindle histiocytes & 3 \\
\hline & & Giant cells & 26 \\
\hline & \multirow{4}{*}{$\begin{array}{l}\text { Arrangement } \\
\text { infiltrate }\end{array}$} & Compact granuloma & 52 \\
\hline & & Illdefined granuloma & 15 \\
\hline & & Diffuse infiltrate & 18 \\
\hline & & Few scattered cells & 11 \\
\hline & & Collar of lymphocytes around granuloma & 52 \\
\hline & & Lymphocytes at a pole of granuloma & 13 \\
\hline & & Infiltrate around appendages & 34 \\
\hline & & Infiltrate around NV bundle & 77 \\
\hline & \multirow[t]{6}{*}{ Status of nerve } & Involved + enlarged & 11 \\
\hline & & Involved & 38 \\
\hline & & Uninvolved & 23 \\
\hline & & Nerve twig & 4 \\
\hline & & Onion skin perineurium & 15 \\
\hline & & Hyalinised & 9 \\
\hline
\end{tabular}

Table-3: Grading of bacillary index in different types of leprosy

\begin{tabular}{|c|c|c|c|c|c|c|c|c|}
\hline \multirow[t]{2}{*}{ Diagnosis } & \multicolumn{6}{|c|}{ Multibacillary } & \multirow[t]{2}{*}{ Paucibacillary } & \multirow[t]{2}{*}{ Grand total } \\
\hline & $1+$ & $2+$ & $3+$ & $4+$ & $5+$ & $6+$ & & \\
\hline IL & $2(22.22 \%)$ & - & - & - & - & - & $7 \quad(77.8 \%)$ & $9(100 \%)$ \\
\hline TT & $2(11.11 \%)$ & - & - & - & - & - & $16(88.89 \%)$ & $18(100 \%)$ \\
\hline BT & $5(16.12 \%)$ & $\begin{array}{c}4 \\
(12.9 \%) \\
\end{array}$ & - & - & - & - & $22(70.96 \%)$ & $31(100 \%)$ \\
\hline $\mathrm{BB}$ & - & - & $1(33.33 \%)$ & $2(66.66 \%)$ & - & - & - & $3(100 \%)$ \\
\hline $\mathrm{BL}$ & - & - & $4(44.44 \%)$ & $5(55.55 \%)$ & - & - & - & $9(100 \%)$ \\
\hline LL & - & - & - & $5(33.33 \%)$ & $4(26.66 \%)$ & $6 \quad(40 \%)$ & - & $15(100 \%)$ \\
\hline $\mathrm{HL}$ & - & - & - & - & - & $3(100 \%)$ & - & $3(100 \%)$ \\
\hline Active disease & $5(83.33 \%)$ & & & & & & $1(16.67 \%)$ & $6(100 \%)$ \\
\hline Inactive disease & $1(16.67 \%)$ & & & & & & $5(83.33 \%)$ & $6(100 \%)$ \\
\hline Grand Total & $15(15 \%)$ & $4(4 \%)$ & $5(5 \%)$ & $12(12 \%)$ & $4(4 \%)$ & $9(9 \%)$ & $51 \quad(51 \%)$ & $100(100 \%)$ \\
\hline
\end{tabular}


Table-4: Clinico-histopathological correlation of leprosy

\begin{tabular}{|c|c|c|c|c|c|c|c|c|c|c|}
\hline \multirow{3}{*}{ Clinical Cases } & \multirow{3}{*}{$\begin{array}{c}\text { Total } \\
\text { Clinical }\end{array}$} & \multicolumn{9}{|c|}{ Histological Cases } \\
\hline & & \multirow[t]{2}{*}{ IL } & \multirow[t]{2}{*}{ TT } & \multirow[t]{2}{*}{ BT } & \multirow[t]{2}{*}{ BB } & \multirow[t]{2}{*}{ BL } & \multirow[t]{2}{*}{$\mathbf{L L}$} & \multirow[t]{2}{*}{ Histoid } & \multicolumn{2}{|c|}{ On MDT } \\
\hline & & & & & & & & & Inactive & Active \\
\hline \multirow{2}{*}{ IL } & 7 & 4 & 1 & 0 & 0 & 0 & 2 & 0 & - & - \\
\hline & $\%$ & 57.14 & 14.28 & & & & 28.57 & & & \\
\hline \multirow{2}{*}{ TT } & 9 & 1 & 7 & 1 & 0 & 0 & 0 & 0 & - & - \\
\hline & $\%$ & 11.11 & 77.77 & 11.11 & & & & & & \\
\hline \multirow{2}{*}{ BT } & 43 & 2 & 9 & 28 & 1 & 2 & 1 & 0 & - & - \\
\hline & $\%$ & 4.65 & 20.93 & 65.11 & 2.32 & 4.65 & 2.32 & & & \\
\hline \multirow{2}{*}{ BB } & 3 & 2 & 1 & 0 & 0 & 0 & 0 & 0 & - & - \\
\hline & $\%$ & 66.66 & 33.33 & & & & & & & \\
\hline \multirow{2}{*}{$\mathrm{BL}$} & 12 & 0 & 0 & 1 & 2 & 6 & 3 & 0 & - & - \\
\hline & $\%$ & & & 8.33 & 16.66 & 50 & 25 & & & \\
\hline \multirow{2}{*}{ LL } & 8 & 0 & 0 & 0 & 0 & 1 & 6 & 1 & - & - \\
\hline & $\%$ & & & & & 12.5 & 75 & 12.5 & & \\
\hline \multirow{2}{*}{ HISTOID } & 3 & 0 & 0 & 0 & 0 & 0 & 1 & 2 & - & - \\
\hline & $\%$ & & & & & & 33.33 & 66.66 & & \\
\hline \multirow{2}{*}{ TYPE 1 RXN } & 1 & 0 & 0 & 1 & 0 & 0 & 0 & 0 & - & - \\
\hline & $\%$ & & & 100 & & & & & & \\
\hline \multirow{2}{*}{ ENL } & & 0 & 0 & 0 & 0 & 0 & 2 & 0 & - & - \\
\hline & $\%$ & & & & & & 100 & & & \\
\hline \multirow{2}{*}{ ON MDT } & 12 & 0 & 0 & 0 & 0 & 0 & 0 & 0 & 6 & 6 \\
\hline & $\%$ & & & & & & & & 50 & 50 \\
\hline $\begin{array}{l}\text { TOTAL } \\
\text { HISTOLOGICAL }\end{array}$ & 100 & 9 & 18 & 31 & 3 & 9 & 15 & 3 & 6 & 6 \\
\hline
\end{tabular}

Chi square $=175.365$ with degree of freedom $=48$. $\mathrm{P}$ value $<0.001$

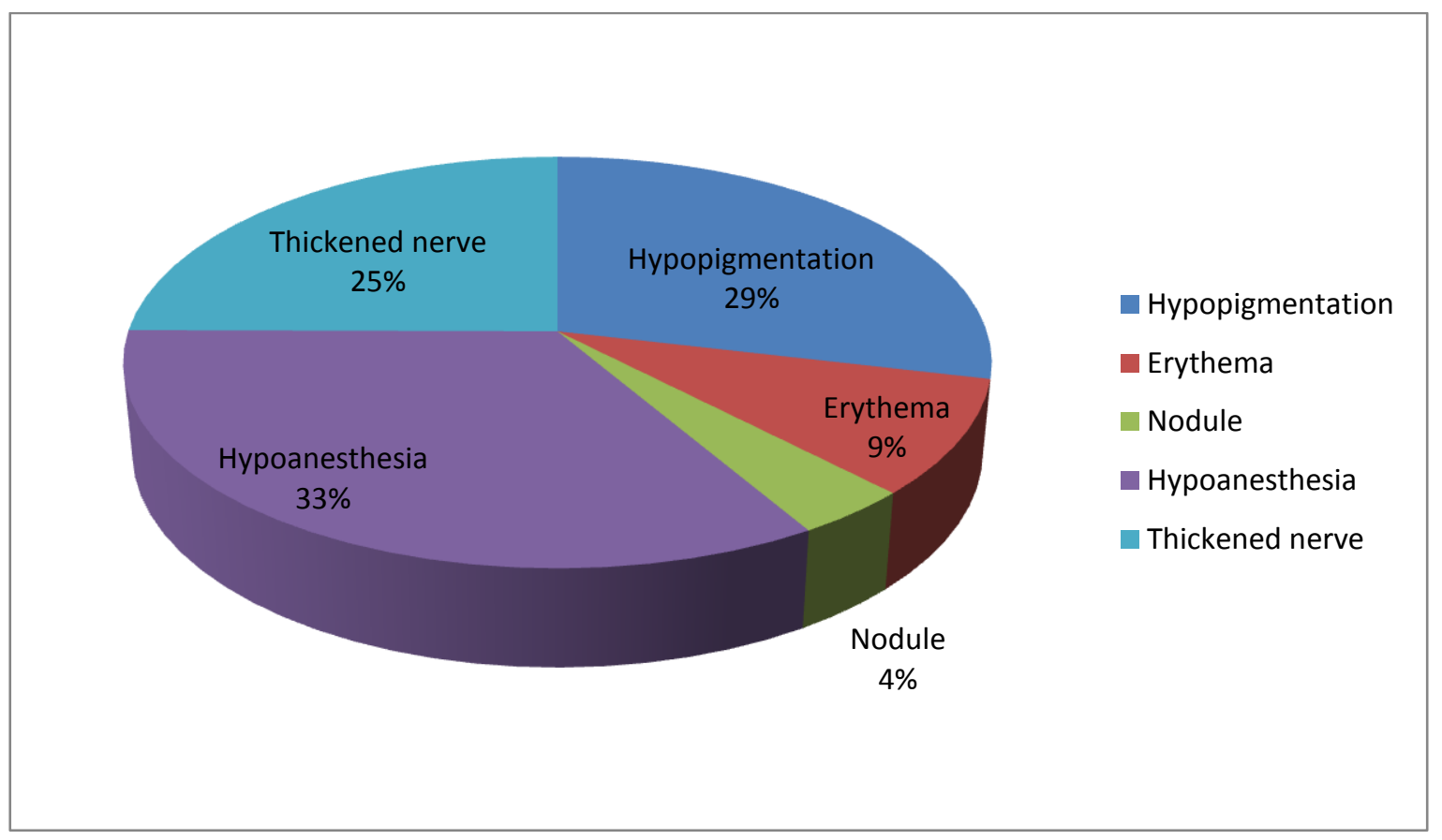

Figure-1: Distribution of cases according to presenting sign/symptom 


\section{JMSCR Vol||07||Issue||04||Page 706-716||April}

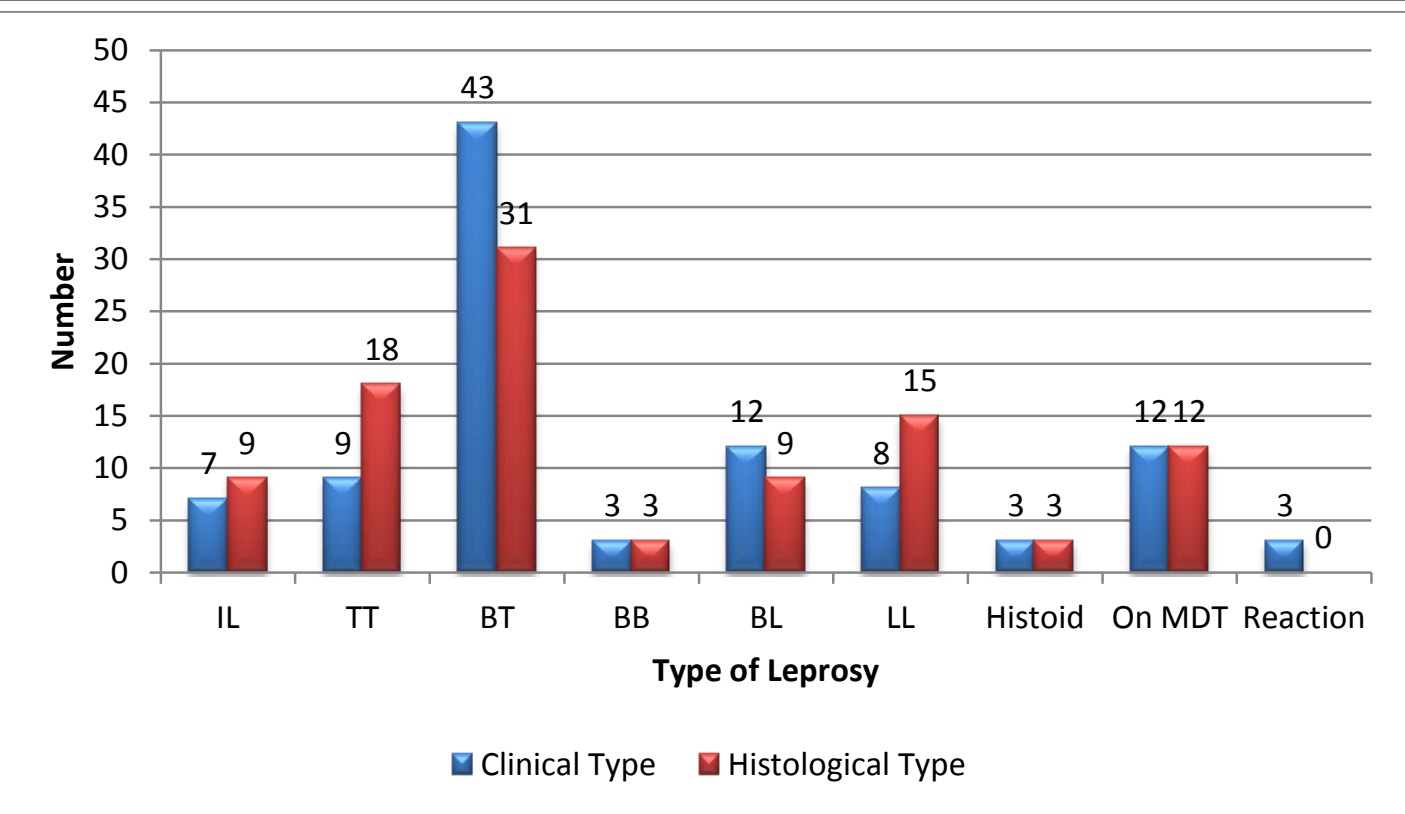

Figure-2: Distribution of cases according to clinical and histopathological diagnosis

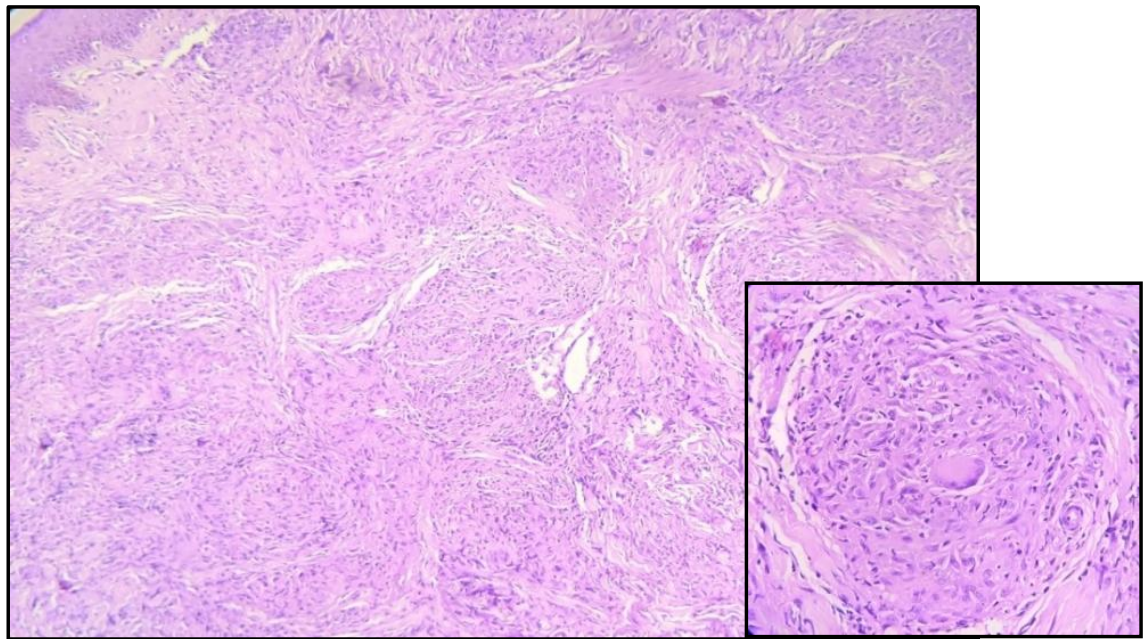

Figure-3: TT-Well defined non caseating granuloma formed by epithelioid cell, langhans giant cell and lymphocyte. [100X, H\&E]



Figure-4: TT-Thinning of epidermis and enchroachment by granulomas. [100X, H\&E] 


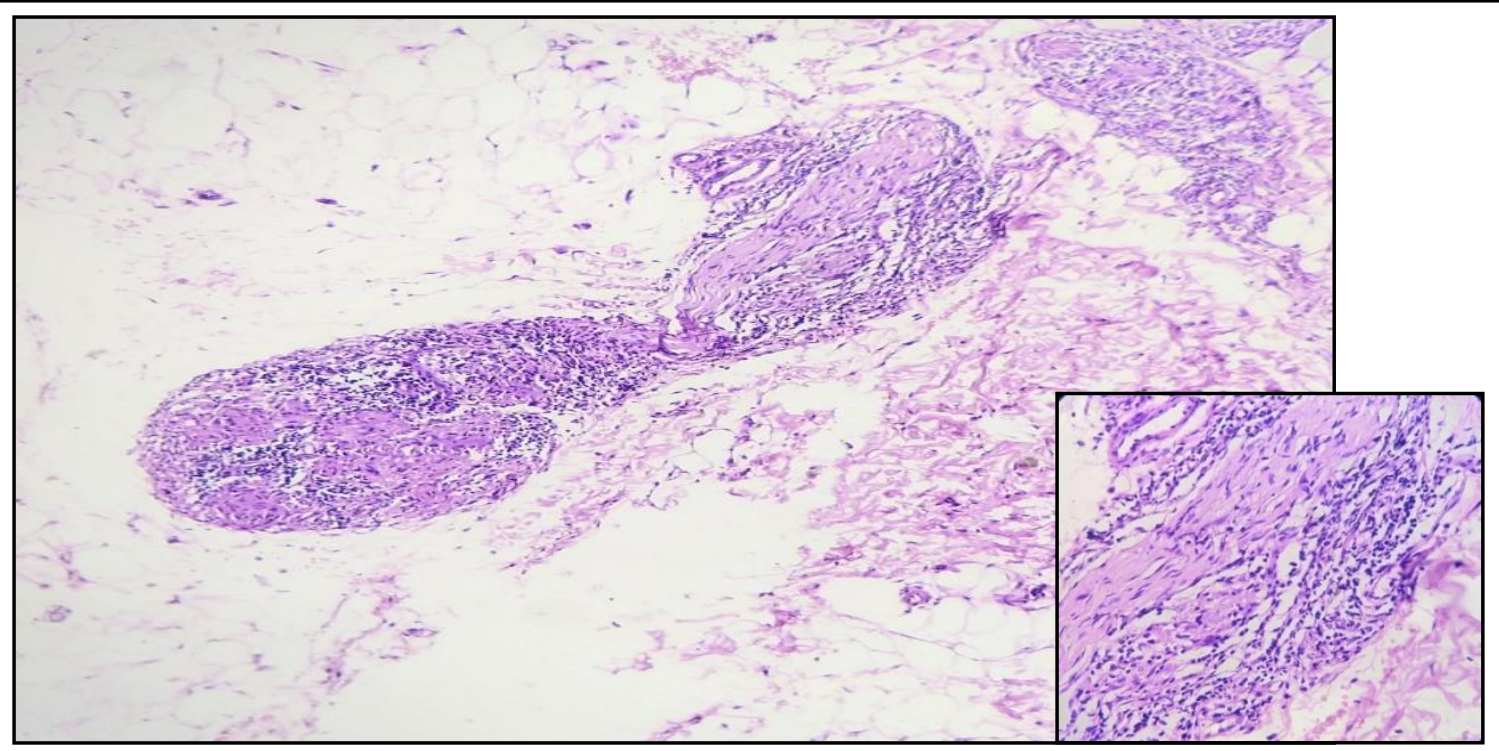

Figure-5: BL-Polar infiltrate around nerve. [100X, H\&E]

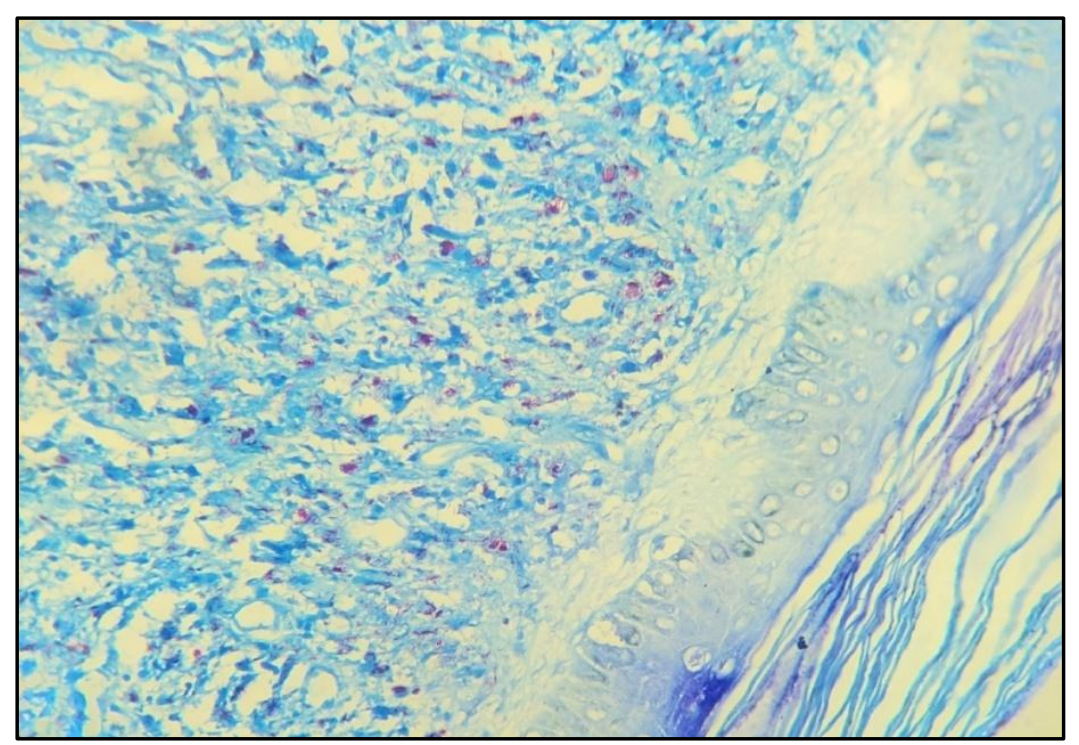

Figure-6: LL-AFB-L positive with $\mathrm{B}=6+$, globi. [Fitefarraco, 400X]

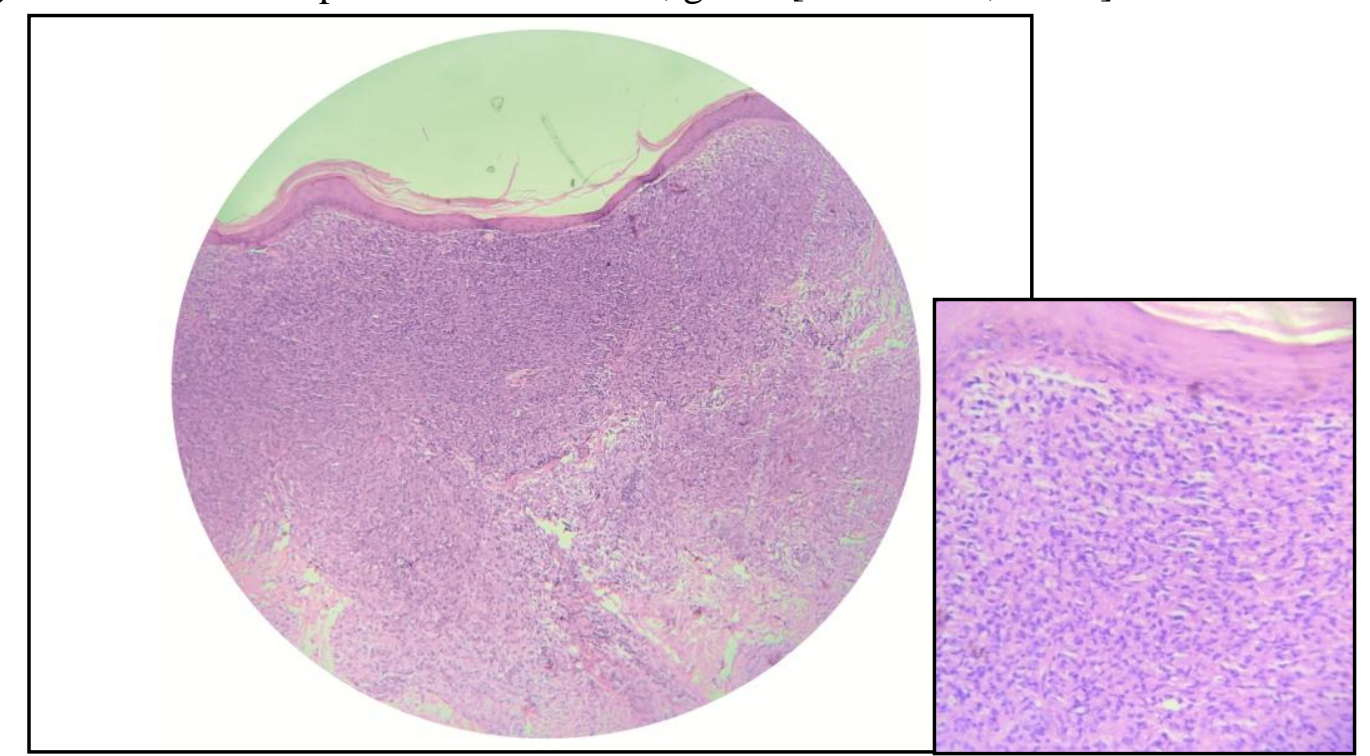

Figure-7: Histoid Leprosy- epidermal atrophy and grenz zone. Dermis is replaced by spindle shaped histiocytes arranged in interlacing bundles. [100X,H\&sE] 


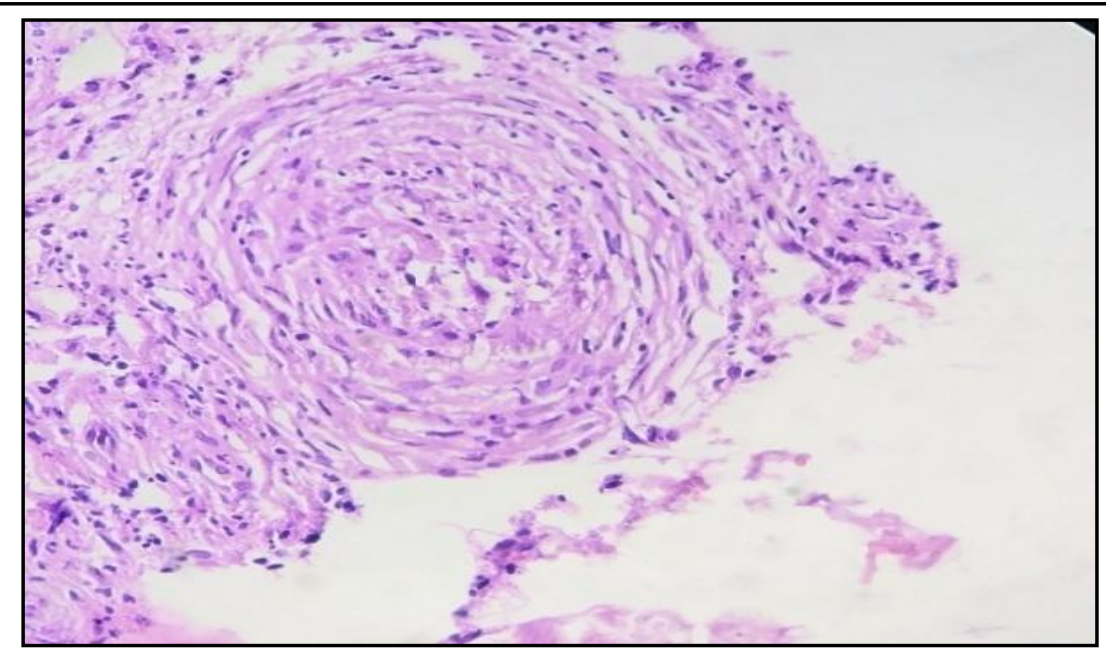

Figure-8: BL- Onion skin perineurium. [400X, H\&E]

\section{Discussion}

Leprosy or Hansen's disease is a slowly progressive, chronic infectious disease caused by the Mycobacterium leprae. It is exclusively a disease of human and only source of infection is a leprosy patient. It is a serious, mutilating and stigmatizing disease in many countries. Early diagnosis and treatment is the most important strategy for its control. It is an important public health problem in our country, with highest prevalence in Uttar Pradesh, Chattisgarh, West Bengal, Bihar, Rajasthan and Maharashtra. It is imperative to have in depth knowledge of leprosy about transmission, histopathology, prevention, classification, diagnosis and treatment at the field level. Gold standard is histopathological examination of skin lesions in leprosy. It is an important tool in accurate diagnosis and classification of leprosy. $^{7}$

The present study was undertaken in the Department of Pathology, over a period of 1 year and 6 months from January 2017 to June 2018. Total 100 cases were studied which had fulfilled inclusion and exclusion criteria. In the present study, majority $(67 \%)$ of the cases were males with a sex ratio of 2.03 in favour of males. The results of studies conducted by Sharma et $\mathrm{al}^{8}$, Mathur et $\mathrm{al}^{9}$, Bijjaragi et $\mathrm{al}^{10}$, Giridhar et $\mathrm{al}^{11}$, Thapa et $\mathrm{al}^{12}$, Singh et $\mathrm{al}^{13}$ and Anusha et al ${ }^{14}$ were in congruence with the results of our study having sex ratio of more than 1 in favour of males. However Suri et $\mathrm{al}^{15}$ reported sex ratio of less than
1 in their study. Male predominance may be because of many factors like industrialization, urbanization and more opportunities for contact in males, social customs and taboos may account for the smaller number of females reporting for treatment to the hospital. ${ }^{7}$

Leprosy is known to occur at all ages ranging from early infancy to very old age. In present study majority (39\%) of the cases were in 31-50 years age group ( $4^{\text {th }}$ and $5^{\text {th }}$ decade) and least $(1 \%)$ number of cases belonged to cases less than 10 years age group ( $1^{\text {st }}$ decade). Study conducted by Sehgal et $\mathrm{al}^{7}$, Anusha et $\mathrm{al}^{14}$, Suri et $\mathrm{al}^{15}$, Kaur et $\mathrm{al}^{16}$ and also found similar results with majority of the cases in 21-40 years age group and least number of cases in less than 10 years age group. Study conducted by Murthy et $\mathrm{al}^{17}$ found $41.1 \%$ of the cases in 11- 30 years age group.

In the present study most common type of clinically diagnosed leprosy was Borderline Tuberculoid. Study conducted by Bijjaragi et $\mathrm{al}^{10}$, Giridhar et $\mathrm{al}^{11}$, Thapa et $\mathrm{al}^{12}$, and Anusha et al ${ }^{14}$ obtained similar results. In present study second most common type of clinically diagnosed leprosy was borderline lepromatous type. Studies conducted by Bijjaragi et $\mathrm{al}^{10}$ and Tekwani et $\mathrm{al}^{18}$ also obtained similar results. However in studies conducted by Giridhar et $\mathrm{al}^{11}$, Thapa et $\mathrm{al}^{12}$ and Anusha et $\mathrm{al}^{14}$ TT was reported as second most common type of clinically diagnosed leprosy. In present study least common leprosy reported clinically was BB. In studies conducted 
by Bijjaragi et $\mathrm{al}^{10}$, Giridhar et $\mathrm{al}^{11}$, Thapa et $\mathrm{al}^{12}$ and Tekwani et $\mathrm{al}^{18}$ similar results were obtained. However in study conducted by Anusha et $\mathrm{al}^{14} \mathrm{BL}$ was least common clinically diagnosed leprosy. In the present study, on histology most of the cases (31\%) showed features of BT subtype, followed by TT (18\%), LL (15\%), BL (9\%), IL $(9 \%)$ cases and $\mathrm{BB}$ as a least common (3\%) type of leprosy on histopathology. In studies conducted by Sharma et $\mathrm{al}^{8}$, Bijjaragi et $\mathrm{al}^{10}$, Giridhar et $\mathrm{al}^{11}$, Thapa et $\mathrm{al}^{12}$, Anusha et $\mathrm{al}^{14}$, Suri et $\mathrm{al}^{15}$ and Tekwani et $\mathrm{al}^{18}$ also found BT as a most common subtype. In the present study, similar to the clinical subtype of leprosy, borderline tuberculoid leprosy constituted major proportion (31\%) of the cases on histopathological study. However in present study TT was second most common histopthological subtype in contrast to BL which was second most common clinical subtype.

An increased awareness towards leprosy due to the increasing efficacy of the public health system as well as to the patients' health seeking behavior makes them present at an early stage to the leprosy clinics, which may contributed to the increased number of cases seen in the borderline tuberculoid group.

In the present study most of the patients presented with hypopigmented lesions (76\%) and with erythematous lesions (24\%). Some patients also had nodules (10\%). Results of the study conducted by Giridhar et $\mathrm{al}^{11}$, Murthy et $\mathrm{al}^{17}$ and Maheswari et al $^{19}$ were in congruence with the results of present study, with majority of the patients with hypopigmented lesions and least number of patients with ulcer.

In the present study, majority of the patients were of paucibacillary type $(51 \%)$ and the rest were of multibacillary type (49\%). Majority of the cases belonged to multibacillary type in BB, BL and LL subtype of leprosy while majority of the cases belonged to paucibacillary type in BT and IL subtype of leprosy. Similar results were also found by Murthy et al ${ }^{17}$.

Amongst cases of BT $32.50 \%$ cases showed presence of acid-fast bacilli with $20 \%$ cases of BI
$1+$ and $12.5 \%$ cases with BI 2+. Rest $67.50 \%$ showed absence of acid-fast bacilli. Giridhar et $\mathrm{al}^{11}$ also observed, $30.95 \%$ cases showed presence of acid-fast bacilli with $18.6 \%$ cases with BI of 1+ and $11.6 \%$ cases with $\mathrm{BI}$ of $2+$ in congruence with our study. Amongst cases of BB 100\% cases showed presence of acid-fast bacilli with $74.53 \%$ cases of BI $1+$ and $25.47 \%$ cases with BI $2+$. Dissimilar to our study, Giridhar et $\mathrm{al}^{11} \mathrm{did}$ not find any AFB positive case of BB subtype. Among cases of BL $100 \%$ cases showed presence of AFB with $44.44 \%$ cases of BL $3+$ and $55.55 \%$ cases of BI 4+. Similar to present study Giridhar et $\mathrm{al}^{11}$ found amongst BL cases, $25 \%$ cases showed BI of $3+, 62.5 \%$ and $12.5 \%$ cases showed BI of $4+$ and 5+ respectively. Amongst cases of LL 100\% cases showed presence of acid-fast bacilli with $2.38 \%$ cases with BI of $3+, 40.48 \%$ cases with BI of $4+$ and $47.62 \%$ cases with BI of $5+$ and $9.52 \%$ with BI of $6+$ but study conducted by Giridhar et $\mathrm{al}^{11}$ found amongst LL cases, $25 \%$ cases were with BI of $5+$ and $75 \%$ cases with BI of $6+$. In other studies lepra bacilli BI was not calculated.

In the current study 9 cases were clinically diagnosed as TT, out of which 7 (77.77\%) were histopathologically confirmed. Of the remaining 2 cases, $1(11.11 \%)$ case showed features of BT and $1(11.11 \%)$ case as IL on histopathology. Similarly Bijjaragi et $\mathrm{al}^{10}$, Giridhar et $\mathrm{al}^{11}$, Thapa et $\mathrm{al}^{12}$ Anusha et al ${ }^{14}$, Tekwani et $\mathrm{al}^{18}$ and Bhushan et al ${ }^{20}$ also observed more than $50 \%$ correlation between clinical and histopathological diagnosis of TT in contrast to observation of Murthy et $\mathrm{al}^{17}$ who observed less than $50 \%$ correlation in TT. Out of the 43 clinically diagnosed BT cases, 28 $(65.11 \%)$ cases correlated histologically, 9 $(20.93 \%)$ cases showed features of TT, $2(4.65 \%)$ cases of BL, 1 (2.32\%) cases of LL and 2 (4.65\%) cases of IL on histopathology. Similar to our finding, studies done by Bijjaragi et $\mathrm{al}^{10}$, Giridhar et $\mathrm{al}^{11}$, Thapa et $\mathrm{al}^{12}$ Anusha et $\mathrm{al}^{14}$, Murthy et $\mathrm{al}^{17}$, Tekwani et $\mathrm{al}^{18}$ and Bhushan et al ${ }^{20}$ had high (more than 50\%) correlation in BT cases on histopathological diagnosis. 
Out of the 3 clinically diagnosed BB cases, 2 $(66.66 \%)$ cases were diagnosed as IL and 1 $(33.33 \%)$ case as TT histologically. None of these showed features of BB histologically. The percentage of agreement was low $(<50 \%)$ in $\mathrm{BB}$ cases in the studies conducted by Murthy et $\mathrm{al}^{17}$, Bijjaragi et $\mathrm{al}^{10}$ and Tekwani et $\mathrm{al}^{18}$ in favour of our finding whereas in contrary to our finding it was high $(>50 \%)$ in studies conducted by Anusha et $\mathrm{al}^{14}$, Suri ${ }^{15}$ and Bhushan et $\mathrm{al}^{20}$. Out of the 12 clinically diagnosed BL cases, $6(50 \%)$ cases correlated histologically, $1(8.33 \%)$ case was confirmed as BT, $2(16.66 \%)$ cases as BB and 3 $(25 \%)$ cases as LL on histopathology. Similar to our finding Giridhar et $\mathrm{al}^{11}$, Anusha et $\mathrm{al}^{14}$ Suri et $\mathrm{al}^{15}$, Tekwani et $\mathrm{al}^{18}$ and Bhushan et $\mathrm{al}^{20}$ also observed $>50 \%$ correlation. However Bijjaragi et $\mathrm{al}^{10}$, Thapa et $\mathrm{al}^{12}$ and Murthy et $\mathrm{al}^{17}$ observed low correlation $(<50 \%)$ in contrast to our finding.

Out of the 8 clinically diagnosed LL cases, majority $6(75 \%)$ of the cases showed histological correlation, $1(12.5 \%)$ case was confirmed as BL and $1(12.5 \%)$ case was confirmed as Histoid leprosy on histopathological diagnosis. Similar to our study percentage of agreement was higher in LL cases in studies done by Bijjaragi et $\mathrm{al}^{10}$, Giridhar et $\mathrm{al}^{11}$, Anusha et $\mathrm{al}^{14}$, Suri et $\mathrm{al}^{15}$, Tekwani et $\mathrm{al}^{18}$ and Bhushan et $\mathrm{al}^{20}$ in contrast to study done by Thapa et $\mathrm{al}^{12}$ and Murthy et al ${ }^{17}$ who observed low correlation $(<50 \%)$ Out of the 7 clinically diagnosed IL cases, 4 (57.14) of the cases correlated histologically, $2(28.57 \%)$ cases showed features of LL and 1 (14.28) of TT on histopathology diagnosis. Similar to our study percentage of agreement was higher in IL cases in the studies conducted by Bijjaragiet al ${ }^{10}$ and Suri et $\mathrm{al}^{15}$. However Giridharet $\mathrm{al}^{11}$, Thapa et $\mathrm{al}^{12}$,Anusha et $\mathrm{al}^{14}$ and Murthy et $\mathrm{al}^{17}$ observed lesser agreement. Out of the 3 clinically diagnosed HL cases, $2(66.66 \%)$ cases were histologically confirmed as HL while 1 (33.33\%) case showed features of LL on histopathology diagnosis. Similar to our study Suriet $\mathrm{al}^{15}$ also found $50 \%$ correlation in HL cases.
In present study overall clinic-histopathological correlation was found in $56(56 \%)$ cases, in congruence to our results studies done by Bijjaragi et $\mathrm{al}^{10}$ and Anusha et $\mathrm{al}^{14}$ also had similar overall correlation while Giridhar et $\mathrm{al}^{11}$, Suri et $\mathrm{al}^{15}$,Murthy et $\mathrm{al}^{17}$, Tekwani et $\mathrm{al}^{18}$ and Bhushan et $\mathrm{al}^{20}$ found higher concordance.

The Ridley-Jopling classification which is widely accepted by histopathologists and leprologists is based on clinical, histopathological and immunological features. The discordance between clinical and histopathological diagnosis was found because the clinical diagnosis was made on the lines of Ridley Jopling classification, even when a histopathological examination had not been done. The variation reported in different studies may be due to difference in number of cases of each type and different criteria used to select the cases. Various factors also influence the histopathological diagnosis such as differences in sample size, choice of the biopsy site, age of the lesion, immunological and treatment status of the patient at the time of biopsy. In some studies, only macular lesions were selected. Our study consisted of cases with all types of lesions such as macules, papules, nodules, etc. A sizable proportion of leprosy cases are in a continuously changing immunological spectrum, i.e. BT-BBBL. In some early cases, clinical signs and symptoms may precede the characteristic tissue changes, or vice versa. There is likelihood of discordance between the clinical and histological observations if a biopsy is taken at an early stage.

\section{Conclusion}

Since no single criterion can be used to diagnose leprosy conclusively, so other contributory factors such as involvement of nerve, skin adnexae, epidermal atrophy, Grenz zone, erosion of the epidermis, granuloma (epithelioid/macrophage) and sbacteriological index has a vital role to arrive at a definitive diagnosis of leprosy. It superemely aids the clinician in better care and management of the leprosy patients. 


\section{References}

1. Bhat RM and Prakash C. Leprosy: An Overview of Pathophysiology. Interdisciplinary Perspective on Infectious Diseases. 2012; Article ID 181089.

2. Tiwari M, Ranabhat S, Maharjan S. Clinicohistopathological correlation of leprosy: A retrospective study of skin biopsy specimens in Chitwan Medical College. International Journal of Medical Science Research and Practice. 2015;2:8-11.

3. Mathur MC, Ghimire RBK, Shrestha P, Kedia SK. Clinicohistopathological Correlation in Leprosy. Kathmandu Univ Med J. 2011;36(4):248-51.

4. Walker SL, Lockwood DN. The clinical and immunological features of leprosy. Br Med Bull. 2006;78:103-21.

5. Park JE, Park K. Epidemiology of communicable diseases. In: Preventive and Social Medicine. Jabalpur: Banarasidas Bhanot; 1991. 215-25.

6. World Health Organization, Global leprosy update 2016.Weekly Epidemiological Record. 2017; 92:501-20.

7. Sehgal VN, Ghorpade A, Saha K. Urban leprosy an appraisal from Northern India. Lepr Rev. 1984;55:159-66.

8. Sharma A, Sharma RK, K C Goswsami, Bardwaj S. Clinico-Histopathological Correlation in Leprosy. Jk Science. 2008;10(3):120-23.

9. Mathur MC, Ghimire RBK, Shrestha P, Kedia SK. Clinicohistopathological Correlation in Leprosy. Kathmandu Univ Med J. 2011;36(4):248-51.

10. Bijjaragi S, Kulkarni V, Suresh KK, Chatura KR and Kumar P. Correlationof clinical and histopathological classification of Leprosy in post elimination era. Indian $\mathbf{J}$ Lepr. 2012;84 :271-5.

11. Giridhar M,Arora G, Lajpal K and Chahal KS. Clinicohistopathological concordance in Leprosy - A Clinical, Histopathological and Bacteriological study of 100 cases. Indian J Lepr. 2012;84:217-25.

12. Thapa DP, Jha AK.Clinico histopathological correlation in leprosy: A tertiary care hospital based study. Our Dermatol Online. 2013;4(3):294-6.

13. Singh A, Gaur R et al. Spectrum of Leprosy Patients with Clinico-Histopathological Correlation: A Hospital Based Study. Asian Journal of Medical Science. 2013;4(4):11-6.

14. Anusha R, Jayaraman J. A study on Clinicohistopathological correlation in Hansen's disease. Int $\mathrm{J}$ Clin and Biomed Res. 2016;2(1):10-12.

15. Suri SK, Iyer RR, Patel DU, Bandil S, Baxi S. Histopathology and Clinicohistopathological correlation in Hansen's disease. J Res Med Den Sci. 2014;2(1):37-44.

16. Kaur I, Indira D, Dogra S, Sharma VK, Das A, Kumar B. Relatively spared Zones in Leprosy: A Clinicopathological Study of 500 Patients. Int J Lep.s 2003;71(3):227-9.

17. Moorthy BN, Kumar P, Chatura KR, Chandrasekhar HR, Basavaraja PK. Histopathological correlation of skin biopsies in leprosy. Indian $\mathbf{J}$ Dermatol Venereol Lepro. 2001;67:299-301.

18. Tekwani D et al., Clinico-Histopathological Correlative Study of Leprosy at a Rural Hospital. JMSCR. 2017;5:22532-41.

19. Maheswari KH. A Clinico Pathological Study of Leprosy (unpublished Doctoral dissertation). Rajiv Gandhi University of Health Sciences. 2012.

20. Bhushan P, Sardana K, Koranne RV, Choudhary M, Manjul P. Diagnosing multibacillary leprosy: A comparative evaluation of diagnostic accuracy of slitskin smear, bacterial index of granuloma and WHO operational classification. Indian J Dermatol Venereol Leprol. 2008;74:322-6. 